\title{
A Dialysis Patient with Systemic Calciphylaxis Exhibiting Rapidly Progressive Visceral Ischemia and Acral Gangrene
}

\author{
Masahito Tamura, Kinya Hiroshige, Akihiko Osajima, Masasuke Soejima, \\ Masayuki TAKAsugi and Akio KuROIWA
}

\begin{abstract}
Systemic calciphylaxis is a rare, poorly understood syndrome of progressive peripheral ischemic necrosis and medial arterial calcification in patients with end-stage renal disease. We report a patient with this syndrome which developed following corticosteroid administration and who ultimately required amputation of the four extremities. Furthermore, cerebral, myocardial, splenic, and intestinal infarctions also developed in parallel with the increment of visceral arterial calcification. No evidence of noticeable hyperparathyroidism or elevation of serum calciumphosphate product was observed. We speculated that, in addition to diabetes mellitus and chronic renal failure while undergoing dialysis therapy, the administration of corticosteroids might act synergistically to cause calciphylaxis.

(Internal Medicine 34: 908-912, 1995)
\end{abstract}

Key words: medial arterial calcification, diabetes mellitus, secondary hyperparathyroidism, corticosteroid

\section{Introduction}

Calciphylaxis is a rare syndrome appearing in patients with long-standing renal failure, and is usually associated with secondary hyperparathyroidism (1-11). Since Selye et al initially described this syndrome and termed it calciphylaxis (1$3)$, this syndrome has been sporadically reported overseas (29), but only one case has been reported in Japan to our knowledge (10).

We describe here a diabetic dialysis patient who received administration of corticosteroids, and in whom acral gangrene and visceral ischemia developed with medial arterial calcification after commencement of hemodialysis. However, there was no evidence of noticeable hyperparathyroidism or elevation of serum calcium-phosphate product.

\section{Case Report}

A 50-year-old woman with an 18-year history of diabetes mellitus was admitted to our institute in January 1993, for chronic renal dysfunction secondary to diabetic nephropathy and progressive pulmonary infiltration. Physical examination revealed systemic hypertension, moist respiratory sound in the right lower lung field, and moderate ankle edema; neither Raynaud's phenomenon nor other skin lesions were observed.

The laboratory findings revealed severe azotemia (serum urea nitrogen; $131 \mathrm{mg} / \mathrm{dl}$, serum creatinine; $7.8 \mathrm{mg} / \mathrm{dl}$ ). She was placed on hemodialysis on the day of admission. The serum calcium and phosphorus concentrations immediately before the start of hemodialysis were $7.0 \mathrm{mg} / \mathrm{dl}$ and $10.5 \mathrm{mg} / \mathrm{dl}$, respectively. These were normalized by dialysis and oral administration of 1,25 dihydroxyvitamin $D_{3}(0.5 \mu \mathrm{g} / \mathrm{day})$. The serum concentrations of alkaline phosphatase and c-PTH on the day of admission were $248.2 \mathrm{IU} / l$ (normal 128.5-406.5 IU/l) and 4.80 $\mathrm{ng} / \mathrm{ml}$ (normal $0-0.70 \mathrm{ng} / \mathrm{ml}$ ), respectively. X-ray examinations of her bones performed at the first admission showed evidence of neither bone disease nor vascular calcification.

Pulmonary infiltration revealed no regression, although overhydration was corrected by hemodialysis and various tentative antibiotic therapies were tried. Based on the clinical diagnosis of bronchiolitis obliterans organizing pneumonia (BOOP), she was given methylprednisolone ( $1 \mathrm{~g} / \mathrm{day}$, iv) for three consecutive days and prednisone (PSL: $50 \mathrm{mg} /$ day orally) thereafter. The oral dose of PSL was ultimately reduced to 25

From the Second Department of Internal Medicine, University of Occupational and Environmental Health, School of Medicine, Kitakyushu Received for publication March 3, 1995; Accepted for publication June 5, 1995

Reprint requests should be addressed to Dr. Masahito Tamura, the Second Department of Internal Medicine, University of Occupational and Environmental Health, School of Medicine, 1-1 Iseigaoka, Yahatanishi-ku, Kitakyushu 807 
$\mathrm{mg} /$ day on hospital day 74 based on the patient's clinical and laboratory recovery from BOOP. She was discharged from our institution on hospital day 147.

A month after discharge, the patient rapidly developed a persistent pain and ischemic skin lesions in all of the appendages of her extremities (Fig. 1), and she was readmitted to our institution in August 1993. The laboratory findings at this time are listed in Table 1. The serum concentration of alkaline phosphatase and c-PTH were $248.2 \mathrm{IU} / \mathrm{l}$ and $3.40 \mathrm{ng} / \mathrm{ml}$, respectively. The serum calcium and phosphorus concentrations were within normal range as described in Table 1 . These concentrations were increased transiently because of the difficulty of dialysis, but were normalized thereafter. Diffuse multiple ringtype arterial deposits, which distinctly outlined the medium to small muscular arteries and which had not been noted during the first admission, were documented by X-ray of the abdomen, forearms, and legs (Fig. 2A, B). Infusion of prostacyclin and
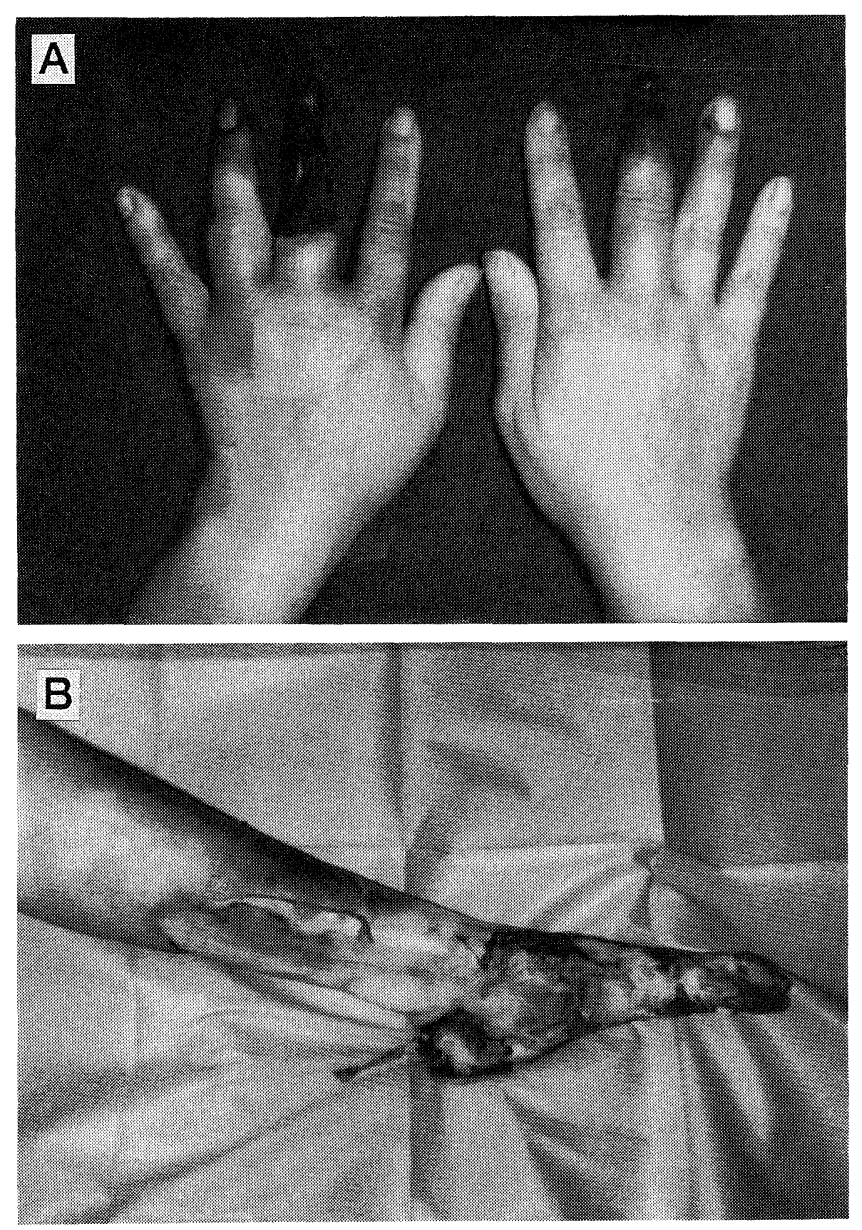

Figure 1. A) Digital gangrene of all fingers of the bilateral hands. B) The left leg showing a large gangrenous area with superficial violaceous discolorations. On the day of admission, the gangrene was only around the distal site of the extremities, but these lesions rapidly expanded to above the knee and below the elbow within a few days. antibiotics failed to improve her symptoms, and the necrosis of the distal site of the four extremities rapidly progressed within a few days. Amputation of the legs above the knees and of the forearms below the elbows was performed on hospital day 29 of the second admission. During the month following the first amputation, two additional amputations were needed in the bilateral lower extremities because of insufficient wound healing of the distal site. The wounds of both legs did not heal thereafter, in spite intensive efforts with various therapeutic regimens. The patient was transferred from hemodialysis to peritoneal dialysis because blood access could not be obtained on hospital day 57.

On hospital day 20, she developed abdominal pains and marked melena. Gastrointestinal fiberscopy revealed a diffused ulcer formation and mucosal edema in the stomach and sigmoid colon. The finding of a multiple ulcer formation in the colon was compatible with ischemic colitis. On hospital day 93, she became drowsy as a result of cerebral infarction in the right middle cerebral artery area, which was revealed by a computed tomography scan of the skull. Generalized streptococcal septicemia developed and she died on hospital day 108. The administration of PSL, orally or intravenously, at a dosage of 10-20 $\mathrm{mg}$ /day had been continued with a gradual tapering until she died (Fig. 3). She had not received any chalybeates throughout the course.

At the time of autopsy, diffused medial calcification involved various small to medium sized visceral arteries (cerebral, coronary, splenic, hepatic, gastric, pancreatic, renal, mesenteric arteries, and a part of the thoracic aorta), but few atherosclerotic lesions were observed in spite of poor control of diabetes mellitus. A postmortem X-ray of the mesenteric arteries showed diffused calcific deposits arranged in so-called pipestemming shape (Fig. 2C). Histologic examination of the small to medium arteries of the extremities revealed diffused medial calcification with intimal fibrous and cellular thickening partly accompanied by microthrombi. The right lateral lobe of the cerebrum was widely necrotic, and the internal carotid artery and the vertebral artery at the circle of Willis contained heavy medial calcific deposits. Hyperplasia of the parathyroid glands was not detected. Three major branches of the coronary artery showed medial calcification and partly mild atherosclerosis with slight luminal narrowing. The gastric and mesenteric arteries also had diffused medial calcification. The stomach and intestine were widely necrotic with mucosal hemorrhaging. In the spleen, there were several wedge-shaped infarctions. No parenchymal calcification of the solid organs was noted.

\section{Discussion}

Calciphylaxis is a potentially lethal complication in patients with chronic renal failure associated with a mortality rate of up to $80 \%$ (7). Ischemic lesions of this syndrome usually begin as superficial violaceous discolorations of the tips of the toes or fingers and may expand to the ankles or thighs (11). Ischemic lesions rarely develop into visceral solid organs. Only ischemic cardiac disease has been described previously to our knowledge 
Table 1. Laboratory Data* on Second Admission

\begin{tabular}{lrlr}
\hline White blood cell & $18,900 / \mathrm{mm}^{3}$ & $\mathrm{Na}$ & $134 \mathrm{mEq} / \mathrm{l}$ \\
Neutrophil & $89 \%$ & $\mathrm{~K}$ & $5.2 \mathrm{mEq} / \mathrm{l}$ \\
Lymphocyte & $9 \%$ & $\mathrm{Cl}$ & $93 \mathrm{mEq} / \mathrm{l}$ \\
Monocyte & $2 \%$ & $\mathrm{Ca}$ & $9.2 \mathrm{mg} / \mathrm{dl}$ \\
Red blood cell & $327 \times 10^{4} / \mathrm{mm}^{3}$ & $\mathrm{IP}$ & $3.6 \mathrm{mg} / \mathrm{dl}$ \\
Hemoglobin & $9.8 \mathrm{~g} / \mathrm{dl}$ & $\mathrm{Fe}$ & $43 \mu \mathrm{g} / \mathrm{dl}$ \\
Hematocrit & $29.6 \%$ & Ferritin & $197.8 \mathrm{ng} / \mathrm{dl}(8-75)$ \\
Platelet & $22.7 \times 10^{4} / \mathrm{mm}^{3}$ & Mg & $1.6 \mathrm{mg} / \mathrm{dl}$ \\
& & C-reactive protein & $10.7 \mathrm{mg} / \mathrm{dl}$ \\
Total protein & $4.3 \mathrm{~g} / \mathrm{dl}$ & Erythrocyte sedimentation rate & $65 \mathrm{~mm} / \mathrm{h}$ \\
Albumin & $2.7 \mathrm{~g} / \mathrm{dl}$ & & $75.90 \mathrm{pg} / \mathrm{ml}(6.50-59.7)$ \\
Total bilirubin & $0.1 \mathrm{~g} / \mathrm{dl}$ & C-terminal parathyroid hormone & $3.40 \mathrm{ng} / \mathrm{dl}(0-0.70)$ \\
Aspartate aminotransferase & $30 \mathrm{IU} / \mathrm{l}$ & Intact-PTH & $(-)$ \\
Alanine aminotransferase & $11 \mathrm{IU} / l$ & Anti-double strained DNA antibody & $(-)$ \\
Lactate dehydrogenase & $231 \mathrm{IU} / l(80-178)$ & Anti-nuclear antibody & $20 \times$ \\
$\gamma$-glutamyl transferase & $76 \mathrm{IU} / l$ & Anti-streptolysin-O & \\
Alkaline phosphatase & $248.2 \mathrm{IU} / l(128.5-406.5)$ & & $11.5 \mathrm{sec}(11.2)$ \\
Cholinesterase & $234 \mathrm{IU} / l$ & Prothrombin time & $24.6 \mathrm{sec}(30.0)$ \\
Urea nitrogen & $55 \mathrm{mg} / \mathrm{dl}$ & Activated partial thromboplastin time & $76.0 \%$ \\
Creatinine & $5.3 \mathrm{mg} / \mathrm{dl}$ & Thrombin time & $518 \mathrm{mg} / \mathrm{dl}$ \\
Uric acid & $7.4 \mathrm{mg} / \mathrm{dl}$ & Fibrinogen & $2.2 \mu \mathrm{g} / \mathrm{ml}$ \\
Creatine phosphokinase & $721 \mathrm{U} / l$ & Fibrinogen degenerate product E $233 \mathrm{ng} / \mathrm{ml}(16.2-62.2)$ \\
MB & $4 \%$ & D-dimer & $112 \%$ \\
MM & $96 \%$ & Anti-thrombin-3 & \\
Glucose & $462 \mathrm{mg} / \mathrm{dl}$ & & \\
\hline
\end{tabular}

*Measured before dialysis.
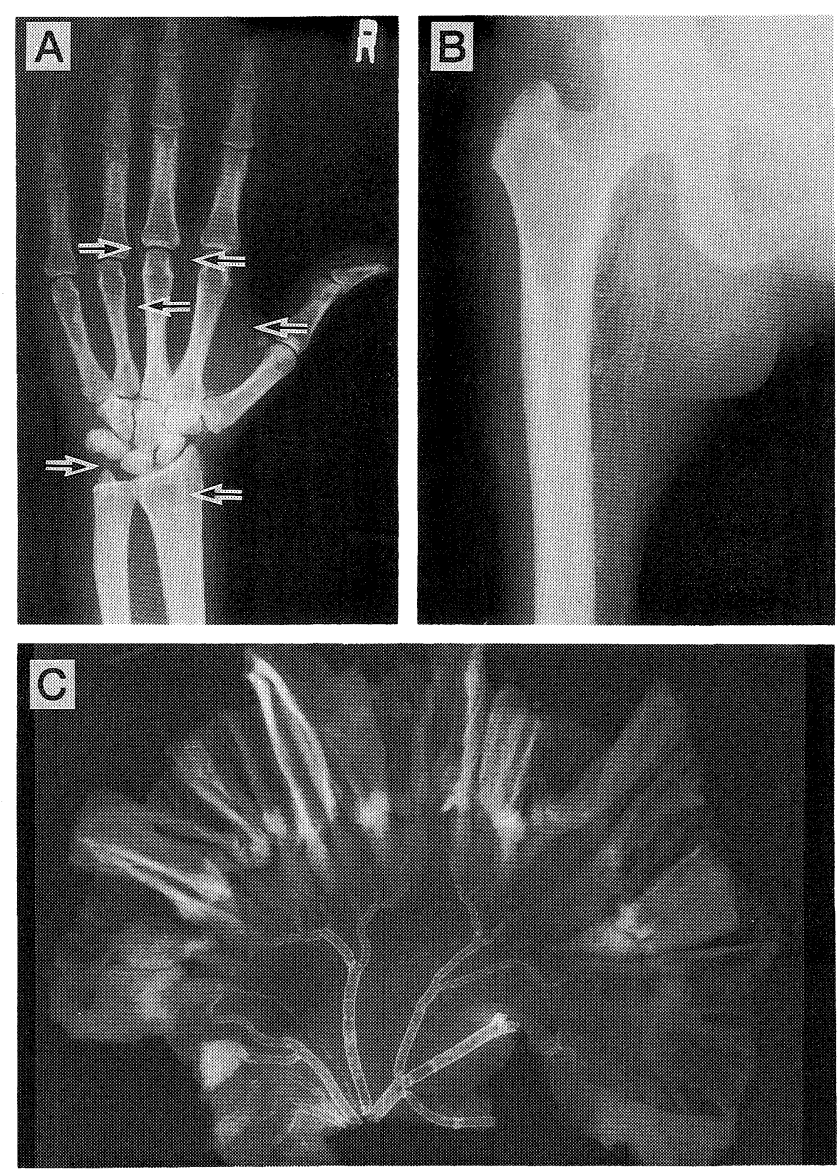

(12). In our patient, diffused medial calcification involved the visceral arteries (cerebral, coronary, splenic, hepatic, gastric, pancreatic, renal, and mesenteric arteries and, partly, the thoracic aorta), and there was circulatory impairment resulting in cerebral, myocardial, splenic, and intestinal infarctions which were resistant to various intensive therapies.

The pathogenesis of the syndrome remains uncertain. Selye et al produced an animal model of calciphylaxis when rats were sensitized by an appropriate biochemical milieu, such as parathyroid extract and dihydrotachysterol, prior to adding various trigger agents (1-3). In fact, most patients with this syndrome have evidence of severe secondary hyperparathyroidism, a high serum phosphorus concentration, and the elevation of serum calcium-phosphorus product (1-11). A favorable response to parathyroidectomy within a few days after surgery suggests that secondary hyperparathyroidism is responsible for the development of calciphylaxis (8).

Figure 2. A) X-ray of the right hand showing diffused, ringlike calcification of palmar digital arteries (arrows), which resembles an arteriogram and is characteristic of medial calcinosis. B) The right leg showing noticeable calcific deposits in the femoral artery and its branches. This calcification could not be detected before commencing hemodialysis. C) A postmortem X-ray of the mesenteric arteries shows diffused, ring-like, calcific deposits along the length of the vessels. 
Methylprednisolone

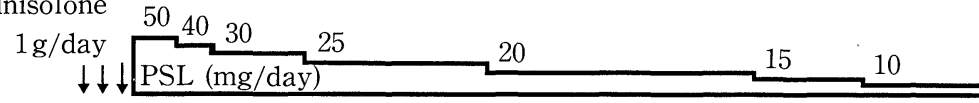

$1,25(\mathrm{OH})_{2}-\mathrm{D}_{3} \quad 0.5 \mu \mathrm{g} /$ day

\begin{tabular}{|l|l|}
\hline Hemodialysis & CAPD \\
\hline
\end{tabular}

C-PTH (ng/ml) 4.80 3.40

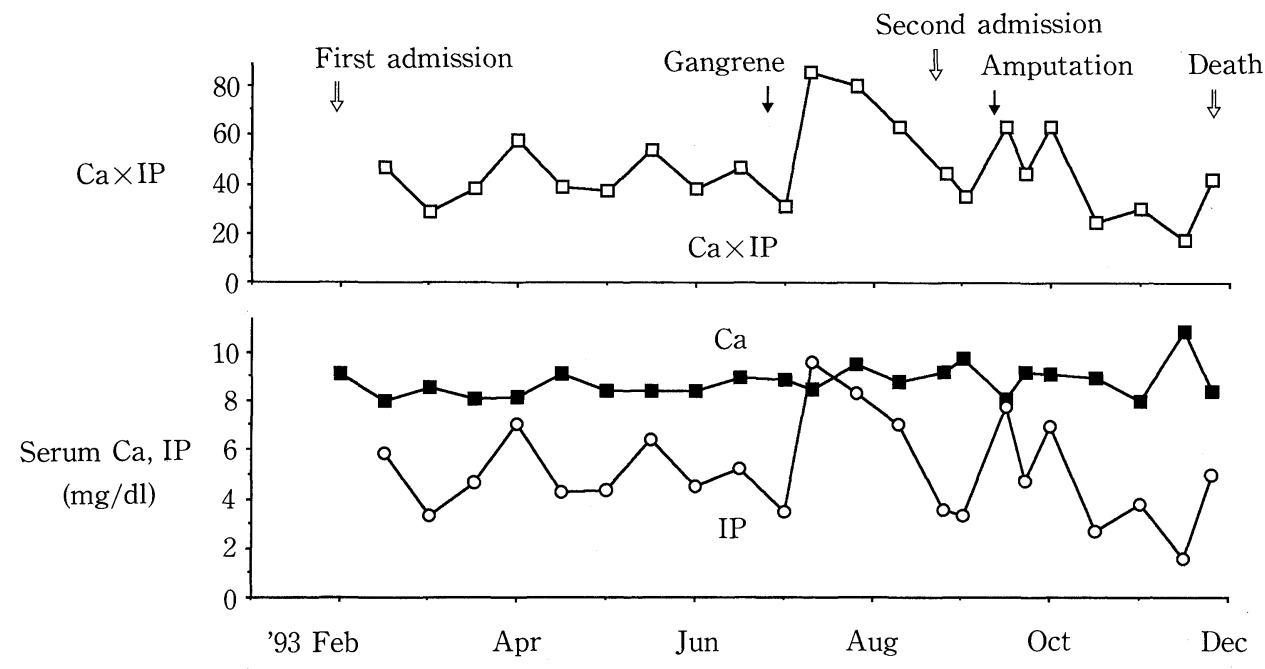

Figure 3. Clinical course. 1,25 $\alpha$-dihydroxyvitamin $D_{3}$ abbreviated as $1,25(\mathrm{OH})_{2}-\mathrm{D}_{3}$; Ca: serum calcium concentration, CAPD: continuous ambulatory peritoneal dialysis, c-PTH: c-terminus parathyroid hormone, IP: serum inorganic phosphate concentration, PSL: prednisolone.

It has been reported that this syndrome is likely to develop in patients who have received glucocorticoids $(4,5,11,13)$. Calciphylaxis often appears in patients with renal transplantation (8), rheumatoid arthritis (13), and chronic renal failure (4, $5,11)$ while receiving these drugs, and this suggests that steroids may also play one of the pathogenic roles in the development of calciphylaxis. Several other reports have described calciphylaxis and medial calcification to be associated with long-standing renal failure (4-6,11), diabetes mellitus (4), administration of vitamin $\mathrm{D}(4,5)$ or iron salts $(2,6)$, the deficiency of protein C (9), and low serum magnesium concentration (14), but these are still in dispute.

In the present, persistent elevation of serum calcium-phosphate product and marked secondary hyperparathyroidism, including hyperplasia of the parathyroid glands at autopsy, were not observed before calciphylaxis developed. Moreover, an atherosclerotic lesion of the arteries, as seen in patients with arteriosclerosis obliterans, was hardly observed at autopsy in spite of the long-standing diabetic state and high dosage administration of steroids. As diffuse calcification of the arteries and progressive gangrene developed after the initiation of hemodialysis and the administration of corticosteroids, we speculate that together with several factors, such as diabetes mellitus or end-stage renal disease, the administration of steroids might have synergistically contributed to the development of calciphylaxis as triggering agents in our patient. Steroid withdrawal may be called for when the deleterious effect of glucocorticoids on the necrotic lesion is more significant than their desirable effect.

\section{References}

1) Selye H. Calciphylaxis. University of Chicago Press, Chicago, 1962.

2) Selye H, Gabbiani G, Strebel R. Sensitization to calciphylaxis by endogenous parathyroid hormone. Endocrinology 71: 554, 1962.

3) Selye H, Gabbiani G, Tuchweder B. Calciphylaxis and parathyroid glands. Rec Prog Horm Res 20: 33, 1964.

4) Wilkinson SP, Stewart WK, Parham DM, Guthrie W. Symmetric gangrene of the extremities in late renal failure: a case report and review of the literature. Q J Med 67: 319, 1988.

5) Gipstein RM, Coburn JW, Adams DA, et al. Calciphylaxis in man, a syndrome of tissue necrosis and vascular calcification in 11 patients with chronic renal failure. Arch Intern Med 136: 1273, 1976.

6) Adrogue HJ, Frazier MR, Zeluff B, Suki WN. Systemic calciphylaxis revisited. Am J Nephrol 1: 177, 1981.

7) Levin A, Mehta RL, Goldstein MB. Mathematical formulation to help identify the patient at risk of ischemic tissue necrosis - a potentially lethal complication of chronic renal failure. Am J Nephrol 13: 448, 1993.

8) Massry SG, Gordon A, Coburn JW, et al. Vascular calcification and peripheral necrosis in a renal transplant recipient. Am J Med 49: 416, 1970.

9) Mehta RL, Scott G, Sloand JA, et al. Skin necrosis associated with acquired protein $\mathrm{C}$ deficiency in patients with renal failure and calciphylaxis. Am J Med 88: 252, 1990. 
10) Kaneda H, Asahi K, Sano K, et al. A long-term hemodialysis patient complicated with systemic calciphylaxis. Jpn J Nephrology 35: 1107, 1993 (Abstract in English).

11) Brenner BM, Rector FC Jr. The Kidney. W. B. Saunders Company, Philadelphia, 1991, p. 2077.

12) Rosen H, Friedmann SA, Raizner AE, Gerstmann K. Azotemic arteriopathy. Am Heart J 84: 250, 1972.

13) Amos RS, Wright V. Mönckeberg's arteriosclerosis and metabolic bone disease. Lancet 2: 248, 1980.

14) Maeema HE, Oreopoulos DG, Rapoport A. Serum magnesium level and arterial calcification in end-stage renal disease. Kidney Int 32: 388, 1987. 